\title{
The Relationship between English Learning and Professional Identity Changes among Iranian PhD Teachers
}

\author{
Vida Rezaei \\ University of Mohaghegh Ardabili, Ardabil, Iran
}

\begin{abstract}
This mix-method study investigated Iranian PhD teachers' professional identity changes associated with English learning. For this reason, $130 \mathrm{PhD}$ teachers (39 female and 91 male) were selected from different majors and from five different Universities of Mohaghegh Ardabili, Azad University of Ardabil, Payame Noor University of Ardabil, Tabriz University, and Allameh Tabataba'i University of Tehran. Teachers exposed to a 19-item questionnaire that designed by Cheung to determine the amount of teachers' commitment to three domains of professional identity, including student needs, school issues, and personal growth and development with a 5-point Likert scale. Then they answered the interview question about the same domains. Main findings of the study are as follow, first, general results indicate that teachers underwent professional identity changes after learning English. Second, female teachers were more committed to the three professional domains than male teachers. Almost all teachers unanimously believed that English learning has a key role in personal growth and development in their professional environment.
\end{abstract}

Index Terms - identity change, language learning, professional identity

\section{INTRODUCTION}

In 1950s, 1960s, and 1970s, people mostly considered second language (L2) teaching and learning as having to do with formal properties of language, like lexicon, pronunciation, and grammar. Then, in 1980s, practitioners and researchers began to realize that learning a second language involves more than gaining linguistic proficiency. Rosaldo (1984), in her study of culture and the individual, showed that in the social environment where people live, the constructs of personhood, language, culture, and identity are intertwined. Since then, research on L2 added a focus on the social context in which languages are learned and taught and began to address the complicated issues of culture, identity, and power.

Identity is a multilayered and complex construct that has tended to be examined from particular points of view by theorists and researchers (Block, 2007). Identity is a necessary aspect of who we are, including our sense of self, gender, race, ethnicity, and religion. It is something that develops during one's whole life; it is not something that one has (Beijaard et al., 2004). The common feature of identity definitions is the idea that it is not something fixed, it is a relational phenomenon. There are different kinds of identity such as teacher identity, student identity, social identity, religious identity, gender identity, professional identity, self-identity, and so on. This study focuses on professional identity.

One of the significant issues in education is teacher identity, which is associated with teachers' commitment (Day et al., 2005), teachers drive a sense of pride in their professionalism when they develop satisfaction with their commitment. The way that teachers define their professional roles is called teacher professional identity (Lasky, 2005). Professional identity has been proved to have significant effects on teachers' performance and development, and learning to teach is fundamentally a process of constructing professional identity rather than knowledge acquisition (e.g., Nguyen, 2008; Varghese et al., 2005).

There are four types of commitment: occupational, identity, caring, and career continuance. In order to make a positive contribution to education, teachers should be able to demonstrate all types of them. In addition to commitment, teacher identity affects many other aspects of education too, such as changing the education policy environment, pedagogy, and the way of teaching. Professional identity is influenced by various factors and conditions both inside and outside the classroom. The studies done on this identity are limited, and in each of them professional identity has been operationalized differently (e.g., Bakhtin, 1981; Caihong, 2011; Coldron \& Smith, 1999; Gee, 2001).

Different studies have investigated multiple kinds of identities from different perspectives. However, subjects of these studies were mostly undergraduate students (e.g., Gao et al., 2005; Hong, 2010; Taylor et al., 2013). In this study, participants were university teachers who were studying for their $\mathrm{PhD}$ degrees or had already obtained their $\mathrm{PhD}$ degrees, and because of the important role of language in constructing individuals' identities, it is aimed to determine the relationship between language learning and professional identity. As Hamachek (1999, p. 209) put it so nicely "consciously we teach what we know, and unconsciously we teach who we are". The teachers' perception of their competence, communication styles, and value systems change after learning a new language (Gao et al., 2005). In order 
to gain an insight into the crucial aspects of teachers' professional lives, like their career decision making, job satisfaction, emotion, motivation, and commitment, we must gain an understanding of their professional identity (Hong, 2010). Therefore, findings obtained by this study can help to uncover the kind of identity changes of teachers that can positively affect their development. The study would be helpful for people who are dealing with teachers' training and teacher education.

\section{LITERATURE REVIEW}

There has been an explosion of interest in identity and language learning over the past 15 years. The powerful connection of identity and language learning is becoming a central concern to many scholars in the field of language education. As a result, the term identity nowadays features in most handbooks and encyclopedias of language learning and teaching (e.g., McKinney \& Norton, 2008; Morgan \& Clarke, 2011; Norton, 2010; Norton \& Toohey, 2002; Ricento, 2005).

Professional identity is a dynamic construct (Barrett, 2008; Varghese, et al., 2005), which has been shown to have a great impact on teachers' performance and development. Teachers have their own interpretations of the curriculum standards and books, their own grasping of student learning, their own teaching styles, on the basis of their professional identities. So the discussion of subjects like teaching and learning cannot be considered without teachers' professional identities (Caihong, 2011). Analyzing professional identity of $\mathrm{PhD}$ university teachers is important because it is closely related to their working life and their prior educational experience (Caihong, 2011).

Two major issues are explored in both general and foreign language (FL) education. The first issue is the multifaceted nature of professional identity and how these facets are related to each other. For example, the characteristics of teachers' identity, the internal or external factors that affect their identity, and so on, are explored (e.g., Beijaard et al., 2000; MacLure, 1993). The second issue, which falls into two factors, is identity formation or construction. One focus is the complexity of identity formation process (e.g., Tsui, 2007); the other is the tension between social structure and personal agency in identity formation (e.g., Coldron \& Smith, 1999; Reynolds, 1996).

Some experts (e.g., Doecke et al., 2004) have referred to four views on teachers' professional identity area of research. There is a psychological view that considers the professional identity development of teachers in the same pace as the growth of the teacher himself. Based on the second view, the discursive view, the factors that control teachers identity formation are their past, present, and future. In the narrative view, a teachers' takes on different identities in different circumstances, for example, becomes a father at home, a teacher in the class, a colleague at work, and so on. Finally, in a dialogic view, a teacher defines his role and others differently in various interactional situations.

Previous studies across different countries have taken teachers professional identity as a key factor in teachers' motivation, retention, and effectiveness (e.g., Avalos \& Aylwin, 2007; Day, et al., 2005; Day et al., 2006; Lasky, 2005; Van den Berg, 2002). The reason is that, 'self' is essential in constructing the way we judge in a given context and interact with the environment. In some studies professional identity is related to teachers' concepts or images of self and they determine the way they develop as a teacher, the way teachers teach, and their ideas about educational reforms (e.g., Knowles, 1992). In some other studies the focus is on teachers' roles in relation with other concepts (e.g., Goodson \& Cole, 1994).

In a quantitative study, Cheung (2008), aimed to develop a teacher professional identity scale in order to measure the professional identity of the Hong Kong in-service teachers. The framework of this study for understanding the professional identity of teachers was through teachers' roles and practices (what they do), and how committed they are to their stated professional practices. The more committed the teachers are, the more likely they are to identify themselves as professional teachers. After a pilot study, 19 items were selected and a Likert scale from one to five was applied. Items were categorized into three factors, student needs, school issues, and personal growth and development. The main participants were 80 in-service, both male and female, teachers. Both pilot and main studies revealed that the scale was valid and reliable for measuring the professional identity. It is suggested that, it will be interesting to compare the professional identity of teachers among different countries.

I used the same questionnaire in my study, since he developed versions of the scale in different languages and he hoped the scale can be used for the teachers of other countries, too. The problem with his study is that it is only quantitative and due to dynamicity of identity it cannot be representative enough.

Caihong (2011) in his study aimed to explore the characteristics of teachers' professional identity and their professional identity changes associated with their academic study toward PhD degrees. This qualitative case research was drawn on interviews with nine EFL teachers in a Chinese university. Major findings of this study include, positive changes that were reported by all nine teachers, both productive identity change and additive identity change (Gao, et al., 2005). Teachers demonstrated discipline-focused, multi-leveled, and achievement-oriented professional identities. The study highlighted the powerful effect of policy upon teachers' identity changes. In this study the number of participants is not representative, we cannot generalize the results.

Abednia (2012) worked on a contribution of a critical EFL teacher education course to Iranian teachers' professional identity reconstruction. Participants were seven teachers. By grounded theory he analyzed pre-course and post-course interviews, class discussions, their reflective journals, and the teacher educator's reflective journals. Three kinds of major shifts occurred in their professional identities: from no orientation or an instrumentalist orientation to a 
critical/transformative orientation of teaching, from conformity to and romanticization of dominant ideologies to critical autonomy, and from a linguistic and technical view to an educational view of second language education. This study has some shortcomings. Due to teaching in many centers, it was impossible to see whether any observable changes happened in teachers' teaching practice or not. Also one of the L2 teaching methodology courses was not part of a typical teacher education program and this may raise doubts about the similarity of the outcome within a teacher education program. Finally, since identity is highly dynamic construct, studies like that need to explore long-term changes in teachers' identities.

In a case study, Nurit Dvir (2015) examined three physically disabled teachers (one with disability of the leg, a deaf teacher, and one suffered from scoliosis) professional identity construction, and their attitudes toward teaching students with disabilities. All participants were students at a teacher-training college in Israel, for both special-education and regular setting. In this qualitative study, by relating their choice of teaching as a profession, they were asked to write their life stories in a professional context for about a year. Narrative analysis revealed a process of identity formation which started by a sense of failure and exclusion in their early life, followed by a turning point, and conclude with a sense of ability to empower their students (with or without disabilities) and a sense of professional self-efficacy. Studies like that can provide many help to students with disabilities, and can give them courage to continue their educational lives and participate in mainstream schools.

Hong (2010) explored different perceptions of beginning and pre-service teachers' professional identity in relation to their decision to leave the profession. A mix-methods design was employed in this study, with 84 participant surveys and collected interview data from 27 of them. He put them in four groups according to their different stages of teaching. He broke down professional identity of teachers into six factors: efficacy, value, emotions, commitment, micropolitics, and knowledge and beliefs. Data analysis revealed that pre-service teachers tended to have naïve and idealistic perceptions of teaching, and emotional burnout was the most salient feature and the main factor that influenced their decision to leave teaching. This emotional burnout was because of failure in classroom management. Teachers believed that school administration was not effective or supportive. So many factors were intertwined in teacher retention and attrition and they considered such a complicated educational phenomena, thus studies need to include other contributing factors too.

Dynamicity of identity necessitates the using of mix-methods in order to analyze identity and its different types from different perspectives. Most studies of different kinds of identities used either qualitative or quantitative designs. The subjects of these studies were mostly undergraduate students or pre-service teachers (e.g., Gao et al., 2005; Hong, 2010; Taylor et al., 2013), in this study, participants will be university teachers who are studying for their PhD degrees or had already obtained their PhD degrees.

Research questions are as follow:

1. Do university teachers undergo professional identity changes after learning English? And do teachers' professional identity changes differ with gender?

2. Is there any correlation among professional identity, gender, and proficiency level?

\section{METHODOLOGY}

\section{A. Participants}

In this study participants were 130 university teachers (39 female and 91 male). Eight people were studying their $\mathrm{PhD}$ but others had already obtained their $\mathrm{PhD}$ degrees. Their ages ranged from 29 to 60, with a mean age of 39.32 years. They were selected from the variety of majors including philosophy, biology, psychology, management, geography, Arabic, history, French, geomorphology, architecture, English, Persian literature, mechanics, agriculture, law, chemistry, civil engineering, geology, mathematics, physics, economics, etc. Twenty five participants were from English major that had high level of proficiency (four upper intermediate, eight advanced, 13 very advanced), among the remaining 105 non English major participants, 46 people had low level of English proficiency (five pre-intermediate, 41 intermediate) and 59 people had high level of proficiency (40 upper intermediate, 15 advanced, four very advanced).

They were selected from five different universities from three different cities. Seventy five participants were from Mohaghegh Ardabili University, 19 from Azad University of Ardabil among who eight people were still studying their $\mathrm{PhD}, 20$ were from Payame Noor University of Ardabil, seven from University of Allameh Tabataba'i in Tehran, and nine from Tabriz University.

\section{B. Instruments}

Questionnaire. In the first part I put a six level scale in order to obtain the participants' level of proficiency. Each level had its own descriptors, according to the descriptions, teachers determined their level of proficiency that whether they are A1 elementary, A2 pre-intermediate, B1 intermediate, B2 upper-intermediate, C1 advanced, or C2 very advanced. Participants who selected A1, A2, or B1 scales in this study, are considered as low proficiency and participants who selected B2, C1, or C2 scales, are considered with high level of proficiency.

In part 2 of the questionnaire I asked some personal information, such as gender, age, major, university, etc. But I didn't ask for any name. The next part consisted of professional identity items. The original questionnaire was in 
English, in order to avoid any misunderstanding, I translated it into Persian and gave the Persian version to all English and non-English major participants.

The questionnaire was developed by Cheung (2008), in order to measure the professional identity of Hong Kong inservice teachers. The scale included 19 items and in both pilot and main study, the scale was found to be reliable and valid for measuring the professional identity. He considered three types of professional domains, student needs domain (7 items), school issues domain (6 items), and personal growth and development domain of teachers (6 items). A Likert scale from one to five was applied in the questionnaire (1= very weakly; $5=$ very strongly). The reliability of this questionnaire was 0.95 .

Interview. By completion of the questionnaire I asked one open-ended interview question and recorded their answers. The interview question was asked in Persian.

\section{Data Analysis}

Data analysis was done by SPSS, through statictical analysis. Correlation formulas were also applied.

\section{RESUlts}

The descriptive statistics for professional identity domains (Table 1) indicated that English learning affected their commitment toward student needs $(M=26.39)$ more than other domains, then the largest mean belonged to personal growth and development domain $(M=24.15)$. Finally school issues by the mean of $M=20.83$ were less open to change in comparison with other domains by learning English.

TABLE 1.

DESCRIPTIVE STATISTICS FOR PROFESSIONAL IDENTITY DOMAINS

\begin{tabular}{llll}
\multicolumn{3}{c}{ DESCRIPTIVE STATISTICS FOR PROFESSIONAL IDENTITY DOMAINS } \\
\hline & $\mathrm{N}$ & Mean & Std. Deviation \\
\hline student needs & 130 & 26.39 & 5.796 \\
school issues & 130 & 20.83 & 5.496 \\
personal growth \& development domain & 130 & 24.15 & 4.866 \\
Valid N (listwise) & 130 & & \\
\hline
\end{tabular}

Total professional identity change showed the mean of $M=71.3$, among whole 130 respondents of this part, 64 teacher scored above the mean. Analyzing those 64 people, in association with their levels of proficiencies, turned out a pie chart that you can see in Figure 1. According to the chart among those 64 respondents, 30 percent were very advanced teachers, 24 percent were advanced, and 18 percent were in upper-intermediate level. Therefore, 72 percent of them had high level of English proficiency and 28 percent had low level of proficiency. This fact can highlight the effect of English learning on teachers' professional identity changes. Professional identity changed with language learning.

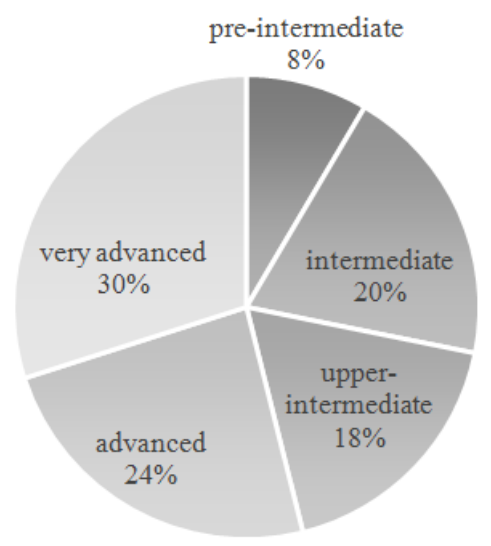

Figure 1. Percentage of teachers scored above mean in their professional identity

\section{A. Gender and Professional Identity Change}

The comparison of the means (Table 2) between males and females on the three variables of student needs domain, school issues domain, and personal growth and development domain showed that female teachers had higher means than male teachers did on all three variables (Fig. 2). In other words, females had a higher commitment. 
TABLE 2.

\begin{tabular}{|c|c|c|c|c|}
\hline & Gender & Mean & Std. Deviation & $\mathrm{N}$ \\
\hline \multirow[t]{3}{*}{ personal growth \& development domain } & Female & 25.03 & 4.771 & 39 \\
\hline & Male & 23.78 & 4.885 & 91 \\
\hline & Total & 24.15 & 4.866 & 130 \\
\hline \multirow[t]{3}{*}{ school issues } & Female & 21.28 & 5.031 & 39 \\
\hline & Male & 20.64 & 5.699 & 91 \\
\hline & Total & 20.83 & 5.496 & 130 \\
\hline \multirow[t]{3}{*}{ student needs } & Female & 26.69 & 5.592 & 39 \\
\hline & Male & 26.26 & 5.906 & 91 \\
\hline & Total & 26.39 & 5.796 & 130 \\
\hline
\end{tabular}

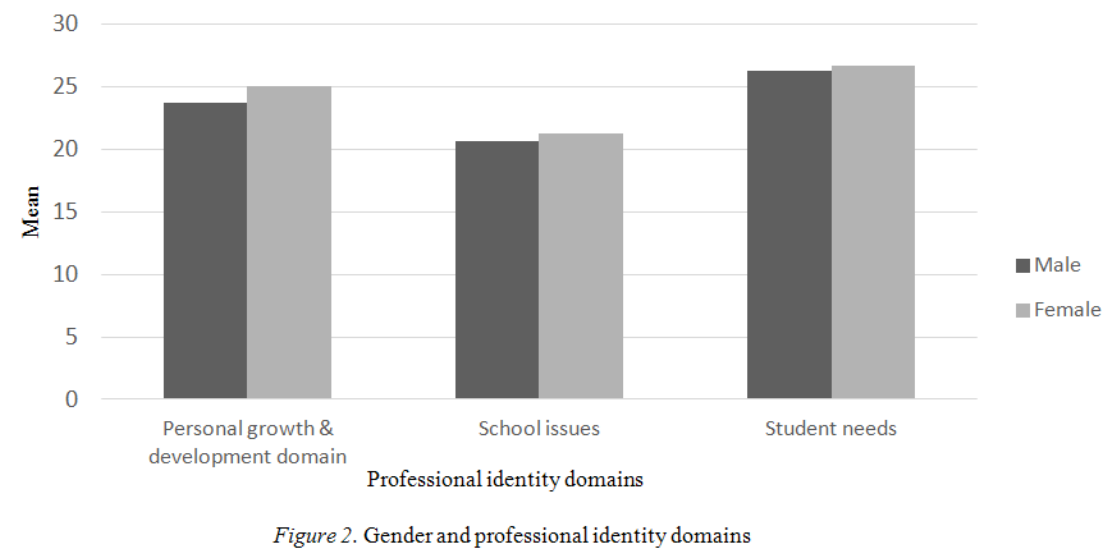

\section{B. Correlation among Professional Identity, Gender, and Proficiency Level}

Professional identity significantly correlates with language proficiency but not with gender. In addition, gender correlates with language proficiency (Table 3 ).

TABLE 3.

CORRELATIONS AMONG PROFESSIONAL IDENTITY, GENDER, AND PROFICIENCY LEVEL

\begin{tabular}{lllll}
\hline & & Gender & language proficiency & Professional identity \\
\hline \multirow{3}{*}{ Gender } & Pearson Correlation & 1 & $-.174^{*}$ & -.065 \\
& Sig. (2-tailed) & & .047 & .459 \\
& $\mathrm{~N}$ & 131 & 131 & 130 \\
language proficiency & Pearson Correlation & $-.174^{*}$ & 1 & $.230^{* *}$ \\
& Sig. (2-tailed) & .047 & & .009 \\
& $\mathrm{~N}$ & 131 & 131 & 130 \\
Professional identity & Pearson Correlation & -.065 & $.230^{* *}$ & 1 \\
& Sig. (2-tailed) & .459 & .009 & 130 \\
\hline
\end{tabular}

*. Correlation is significant at the 0.05 level (2-tailed).

**. Correlation is significant at the 0.01 level (2-tailed).

\section{DisCUSSION AND CONCLUSION}

\section{A. Discussion}

This study defined professional identity as the level of commitment of teachers (Cheung, 2008). Teachers respectively show the highest level of commitment in student needs domain, personal growth and development domain, and finally school issues domain. Analyzing data indicated that 72 percent of teachers who scored above the mean in their professional identity were the teachers that had high levels of proficiencies. As a result it can be concluded that English learning can lead to professional identity changes of teachers.

Student needs domain had the highest mean, and showed that teachers are there for their students; the first priority of a teacher is the progress and success of his/her students. This domain is even more important than their own personal growth and development. Teachers said with or without English learning, they have some responsibilities toward students and they should do their duties, it showed that sense of responsibility is not exposed by external power, it is a natural response to what we care about (Fromm, 1947). School issues with a significant difference was in the third place, some of the teachers believed that school goals were not separated from their own goals or from their students' goals. In order to preserve their job, teachers had to follow all the rules and objectives of the center, at the beginning they didn't have a critical view and could not import their own ideas much, but as their professional identity develop; they shift to a 
critical autonomy (Abednia, 2012). Teachers believed that one of the most important limitations in the development of the professional identity was the lack of support from administration (Zare-ee \& Ghasedi, 2014), especially in Azad university.

In interview all teachers, non-exceptionally, believed that learning English can make gulf of difference in their profession, specially due to scientific and educational environment in which they work in. English learning paves the way of both their educational and professional paths. They said by learning English their personal growth in their profession will be accelerated since English is believed to be the language of science. On the other hand, they will be able to guide and help their students in a more efficient way by providing more up to date information for them and by encouraging them to learn English. Even sometimes when the teacher speaks English in the class or uses technical words in English, automatically students get motivated to learn it. Teachers, specially non-English major ones, believed in Iranian classrooms students usually obey and appreciate the teacher who knows foreign languages well, while Taylor et al. (2013) found out, in European context being appreciated with students or colleagues as an individual person do not depend on educational background.

Female teachers showed higher level of commitment compared to male teachers. It is considered an interesting result since in Iranian context males may seem to be more serious, responsible, and committed to their profession, and in a condition in which the number of male teachers in universities is much higher than females. Specially in personal growth and development domain the difference is more significant. A female teacher said, "When as a woman and as a person who wears hijab I started to use English or French words during my teaching, or when students found out I have translated some books, it really impresses them." In a study by Cheung (2008) it was completely vice versa, in all three variables of professional identity, male in-service teachers scored higher than female in-service teachers in Hong Kong.

About school issues teachers declared that they have some duties and there are some expectations from them in their working environment and toward students, with or without learning English they try to meet this expectations. Some teachers with high level of proficiency said by learning English they start to read some books other than their own majors, and this self-study really impressed their lives in a positive way.

Professional identity is significantly correlated with proficiency level but not with gender. Proficiency level is also correlated with gender. Unlike proficiency level, there is not much relationship between the gender of a person and his/her professional identity.

\section{B. Conclusion}

After learning English, university teachers underwent professional identity change. Their level of commitment toward students needs raised more than other domains. University teachers are in an academic environment so in this condition acquiring English is vital and can make lots of differences in teachers' personal, educational, and professional progress. Progress occurs under one condition that the person starts to use the language. English is just like a machine that can facilitate the progress through using it, having the machine itself without using cannot be helpful. In educational environments they should give more weight to learning English. So professional identity differs with gender, proficiency level, and major.

Finally, learning is a kind of change, so language acquisition as a kind of learning has the ability to change the learner. Language is just like a key, the more languages we learn, the more keys we have to open up wide horizons in front of ourselves. People, their languages, their believes, their culture, and their life style are all different all over the world; the only common language in the world is the language of science, learners can both affect and be affected by the people whom they are interacting. Identity as a dynamic phenomenon is always prone to change, and this change depending on the situation might be as a result of a new environment, a new language, or even a new profession.

\section{Implications of the Study}

The present study highlighted the role of the learning English in identity change. In Iranian context studies of this topic are limited. The person is limited inside a cocoon, through learning English, he/she would break limits and would gain different colors. Teachers stated that the amount of attention toward learning English should increase, and policy makers should place more emphasis in our educational system toward learning English. Some of them claimed that we had enough knowledge but we didn't have the tool, which is the English, to share it with the world.

This study would be helpful for people who are dealing with teachers' training, teacher education, syllabus designers, and material developers, to help pre-service teachers to develop a positive identity. Findings obtained by this study can motivate other teachers to go for English learning. Then their learning will also affect and encourage their students to learn English. I was surprised that still there are many university teachers who are not proficient enough in English. The study uncovered the needs and problems of educational environments from teachers' point of view, so universities can make use of the results of such a studies to alleviate their shortcomings and pay attention to teachers' needs.

\section{Suggestions for Further Research}

People who wish to do some further research in this area should consider some important points. First in designing language proficiency scale I mostly insist on to what extent they have the ability to speak and understand English, some of the teachers mentioned that while they are good at reading comprehension, translation, and understanding their own major's specialized words and readings, they cannot speak well in English. In designing your proficiency scale, you 
should take this into consideration. Second, in order to make sure that how much is the effect of language learning on identity change, it is better to analyze samples before and then after learning the language, under this condition we can talk with more confidence. Another recommendation for further study is adding the element of motivation. It is one of the important aspects of language learning, and it might be an influencing factor in identity changes. On the other hand, many university teachers are not proficient enough in English while it is important for their progress, you can analyze why they do not start learning English, and what kind of motivations lead teachers to acquire other languages. Also by having some samples with lower level of education and comparing them with $\mathrm{PhD}$ teachers we can find out the changes are because of higher education or learning English.

\section{REFERENCES}

[1] Abednia, A. (2012). Teachers' professional identity: Contributions of a critical EFL teacher education course in Iran. Teaching and Teacher Education 28, 706-717.

[2] Avalos, B. \& P. Aylwin (2007). How young teachers experience their professional work in Chile. Teaching and Teacher Education 23, 515-528.

[3] Bakhtin, M. M. (1981). The dialogic imagination: Four essays by M.M. Bakhtin. Austin, TX: University of Texas Press.

[4] Barrett, M. A. (2008). Capturing the difference: Primary school teacher identity in Tanzania. International Journal of Educational development 28.5, 496-507.

[5] Beijaard, D., N. Verloop \& J. D. Vermunt. (2000). Teachers' perceptions of professional identity: An exploratory study from a personal knowledge perspective. Teaching and Teacher Education 16, 749-764.

[6] Beijaard, D., P. C. Meijer \& N. Verloop (2004). Reconsidering research on teachers' professional identity. Teaching and Teacher Education 20, 107-128.

[7] Block, D. (2007). Second language identities. London: Continuum.

[8] Caihong, H. (2011). Changes and characteristics of EFL teachers' professional identity: The cases of nine university teachers. Chinese Journal of Applied Linguistics (Quarterly) 34.1, 3-21.

[9] Cheung, H. Y. (2008). Measuring the professional identity of Hong Kong in-service teachers. Journal of In-service Education 34.3, 375-390.

[10] Coldron, J. \& R. Smith (1999). Active location in teachers' construction of their professional identities. Journal of Curriculum Studies 31.6, 711-726.

[11] Day, C., B. Elliot \& A. Kington (2005). Reform standards and teacher identity: Chalenges of sustaining commitment. Teaching and Teacher Education 21.5, 563-577.

[12] Day, C., A. Kington, G. Stobart \& P. Sammons. (2006). The personal and professional selves of teachers: Stable and unstable identities. British Educational Research Journal 32.4, 601-616.

[13] Devir, N. (2015). Does physical disability affect the construction of professional identity? Narratives of student teachers with physical disabilities. Teaching and Teacher Education 52, 56-65.

[14] Doecke, B., T. Locke \& A. Petrosky. (2004). Explaining ourselves (to ourselves): English teachers, professional identity and change. English in Australia 139, 103-112.

[15] Fromm, E. (1947). Man for himself: An Inquiry into the Psychology of Ethics. New York: Fawcett Premier.

[16] Gao, Y. H., Y. Cheng, Y. Zhao \& Y. Zhou (2005). Self-identity changes and English learning among Chinese undergraduates. World English 24.1, 39-51.

[17] Gee, J. P. (2001). Identity as an analytic lens for research in education. In W. G. Secada (Ed.), Review of research in education. Washington, DC: American Educational Research Association, 99-125.

[18] Goodson, I. F. \& A. L. Cole (1994). Exploring the teacher's professional knowledge: Constructing identity and community. Teacher Education Quarterly 21.1, 85-105.

[19] Hamachek, D. (1999). Effective teachers: What they do, how they do it, and the importance of selfknowledge. In R. P. Lipka \& T. M. Brinthaupt (Eds.), The role of self in teacher development. Albany, NY: State University of New York Press, 189-224..

[20] Hong, J. Y. (2010). Pre-service and beginning teachers' professional identity and its relation to dropping out of the profession. Teaching and Teacher Education 26, 1530-1543.

[21] Knowles, G. J. (1992). Models for understanding pre-service and beginning teachers' biographies: Illustrations from case studies. In I. F. Goodson (Ed.), studying teachers' lives. London: Routledge, 99-152.

[22] Lasky, S. (2005). A sociocultural approach to understanding teacher identity, agency and professional vulnerability in a cont ext of secondary school reform. Teaching and Teacher Education 21.8, 899-916.

[23] MacLure, M. (1993). Arguing for yourself: Identity as an organizing principle in teachers' jobs and lives. British Educational Research Journal 19.4, 311-322.

[24] McKinney, C. \& B. Norton (2008). Identity in language and literacy education. In B. Spolsky \& F. Hult (Eds.), The handbook of educational linguistics. Malden: Blackwell, 192-205.

[25] Morgan, B. \& M. Clarke (2011). Identity in second language teaching and learning. In E. Hinkel (ed.), Handbook of research in second language teaching and learning. (2nd edn) New York: Routledge, 817-836.

[26] Nguyen, H. T. (2008). Conception of teaching by five Vietnamese American preservice teachers. Journal of Language, Identity \& Education 7.2, 113-136.

[27] Norton, B. (2010). Language and identity. In N. Hornberger \& S. McKay (Eds.), Sociolinguistics and language education. Bristol, UK: Multilingual Matters, 349-369.

[28] Norton, B. \& K. Toohey (2002). Identity and language learning. In R. B. Kaplan (Ed.), The Oxford handbook of applied linguistics. New York: Oxford University Press, 115-123.

[29] Reynolds, C. (1996). Cultural scripts for teachers: Identities and their relations to workplace landscapes. In M. Kompf, W. R. Bond, D. Dworet \& R. T. Boak (Eds.), Changing Research and Practice. Philadelphia: The Falmer Press, 69-77. 
[30] Ricento, T. (2005). Considerations of identity in L2 learning. In E. Hinkel (Ed.), Handbook of research on second language teaching and learning. Mahwah, NJ: Lawrence Erlbaum, 895-911.

[31] Rosaldo, M. (1984). Toward an anthropology of self and feeling. In R. Shweder \& R. LeVine (Eds.), Culture theory. Cambridge, UK: Cambridge University Press, 137-157.

[32] Taylor, F., V. Busse, L. Gagova, M. Marsden \& B. Roosken (2013). Identity in foreign language learning and teaching: Why listening to our students' and teachers' voices really matters. ELT Research Papers, 13-02, London, British Council, University of York.

[33] Tusi, A. B. M. (2007). Complexities of identity formation: A narrative inquiry of an EFL teacher. TESOL Quarterly 41.4, 657680.

[34] Van den Berg, R. (2002). Teachers' meanings regarding educational practice. Review of Educational Research 72.4, 577-625.

[35] Varghese, M., B.Morgan, B. Johnston \& K. A. Johnson. (2005). Theorizing language teaching identity: Three perspectives and beyond. Journal of Language, Identity \& Education 4.1, 21-44.

[36] Zare-ee, A. \& F. Ghasedi. (2014). Professional identity construction issues in becoming an English teacher. Procedia-Social and Behavioral Sciences 98, 1991-1995.

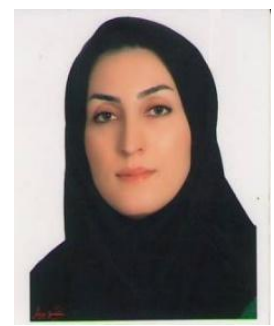

Vida Rezaei was born in Ardabil, in 1988. Rezaei has a B.S. in geology from Payame Noor University of Ardabil 2010, a B.A. in English teaching from the University of Mohaghegh Ardabili 2015, and an M.A. in English teaching from the University of Mohaghegh Ardabili 2017.

On her M.A. thesis, she studied on the relationship among English proficiency, self-identity change, social identity change, and professional identity change. 